\title{
Posterior hemivertebra resection and short- segment fusion with lateral mass screws in congenital scoliosis: a novel strategy for the resource-limited setting
}

Mohammad Zarei ${ }^{1}$, Ehsan Ghadimi ${ }^{1}$, Nima Bagheri ${ }^{1}$, Seyed Mir Mansour Moazen Jamshidi ${ }^{1}$, Alireza Moharrami ${ }^{1}$, Mersad Moosavi ${ }^{1}$ and Soroush Baghdadi ${ }^{1,2^{*}}$ (i)

\begin{abstract}
Background: Posterior hemivertebra resection and short-segment fusion with pedicle screws are an established treatment in congenital scoliosis, which require pediatric-specific instrumentation. The purpose of this study was to report the results of utilizing cervical lateral mass screws instead of pedicle screws in the treatment of congenital scoliosis in children younger than 5 years old.

Methods: In an IRB-approved retrospective chart review study, patients $<5$ years old with congenital scoliosis who underwent posterior hemivertebra resection and fusion with lateral mass screws from 2013 to 2017 were included. Demographic information, pre- and post-operative radiographs, complications, and outcomes were extracted from the charts.

Results: Twenty-three patients were included in the final analysis with a mean age of 40 months, of which 14 were female. Patients were followed for a mean of $51.3 \pm 13.2$ months. The mean blood loss was $210 \mathrm{ml}$, and patients were hospitalized for a mean of 4 days post-operatively. The correction rate of the main coronal curve, compensatory cranial curve, compensatory caudal curve, and segmental sagittal curve was $74.8 \%, 68 \%, 65.2 \%$, and $68.9 \%$, respectively. Three complications were observed: one intra-operative pedicle fracture, one case of implant failure, and one deep surgical-site infection, all of which were successfully managed.

Conclusions: Our findings suggest that adult lateral mass screws can be used for transpedicular fixation of the thoracic and lumbar vertebrae in low-resource settings where pediatric-specific pedicle instruments are not readily available. The correction rate, outcomes, and complications are similar and comparable to pediatric-specific pedicle screws, in addition to being low-profile and less bulky compared to adult implants.
\end{abstract}

Keywords: Congenital scoliosis, Congenital deformity, Hemivertebra, Hemivertebra resection, Lateral mass screw, Posterior spinal fusion, Complication

\footnotetext{
* Correspondence: Baghdadi.soroush@gmail.com

'Joint Reconstruction Research Center, Tehran University of Medical Sciences,

Keshavarz Blvd, Tehran 1419733141, Iran

${ }^{2}$ The Children's Hospital of Philadelphia, Division of Orthopaedics,

Philadelphia, PA, USA
}

C C The Author(s). 2021 Open Access This article is licensed under a Creative Commons Attribution 4.0 International License, which permits use, sharing, adaptation, distribution and reproduction in any medium or format, as long as you give appropriate credit to the original author(s) and the source, provide a link to the Creative Commons licence, and indicate if changes were made. The images or other third party material in this article are included in the article's Creative Commons licence, unless indicated otherwise in a credit line to the material. If material is not included in the article's Creative Commons licence and your intended use is not permitted by statutory regulation or exceeds the permitted use, you will need to obtain permission directly from the copyright holder. To view a copy of this licence, visit http://creativecommons.org/licenses/by/4.0/ The Creative Commons Public Domain Dedication waiver (http://creativecommons.org/publicdomain/zero/1.0/) applies to the data made available in this article, unless otherwise stated in a credit line to the data. 


\section{Background}

Hemivertebra is the most common form of congenital scoliosis, resulting from a failure of normal vertebral formation [1]. The treatment is challenging in many cases and largely depends on the number, location, and type of congenital hemivertebra, as well as age and concurrent pathologies. Long unfused segments are amenable to guided growth procedures. However, isolated hemivertebra have the highest potential for curve progression, and as such, are best treated with resection and shortsegment posterior spinal fusion [2]. Such a strategy has been shown to provide excellent results, especially when done early (3-5 years) [3].

Posterior fusion in young children requires utilizing pediatric-specific instrumentation systems, as $3.5-\mathrm{mm}$ pedicle screws are often needed due to the small size of the pediatric vertebrae. Pediatric-specific instruments are not available in many centers, especially in the developing world, due to their cost and limited applications $[4,5]$. An alternative is to operate when the patient is older and use adult 4.5- or 5-mm pedicle screws. However, these screws are bulky, and such hardware's prominence might be problematic and even cause the overlying skin's breakdown (Fig. 1). Furthermore, there is a potential risk of pedicle screw fracture when using adult-type screws, which might be challenging to manage and cause devastating complications.

At our institution in Tehran, Iran, we have had limited and intermittent access to pediatric pedicle screw instrumentation throughout the years and have been using cervical lateral mass screws and rods as pedicle screws to treat congenital scoliosis. Lateral mass screws are low-profile (Fig. 2), are more readily available, and in our experience, have been a good alternative to pediatric pedicle screws. Therefore, this study was performed to report the posterior fusion results with cervical lateral mass screws in isolated hemivertebra treatment and evaluate possible complications and safety issues.

\section{Methods}

After obtaining IRB approval, a retrospective chart review was done to identify patients who underwent hemivertebra resection and posterior fusion at our institution between 2013 and 2017. Patients under the age of 5 years were selected because the ideal application of this technique is in this age group. Patients who underwent a posterior fusion with lateral mass screws were selected and included in the final analysis from this database. Exclusion criteria included patients diagnosed with noncongenital curves, patients older than 5 years of age, and patients who required extensive surgery, defined as more than a single-level hemivertebra resection. Patients who had undergone previous surgeries were also excluded, as well as patients with $<2$ years of follow-up. All surgeries were done by a fellowship-trained orthopedic spine surgeon (MZ) at a referral spine center.

Demographic data were collected, and radiographic measurements were performed on pre-operative, immediate post-operative, and follow-up standing full spine posteroanterior and lateral radiographs. The main curve, compensatory cranial curve, and compensatory caudal curve were identified and measured by the senior author. To assess sagittal plane correction, segmental kyphosis or lordosis was compared with Bernhardt and Bridwell's corresponding standard values and was reported as positive for kyphosis and negative for lordosis [6]. Intraoperative blood loss, operative time, and complications were extracted from the operative notes. Complications,

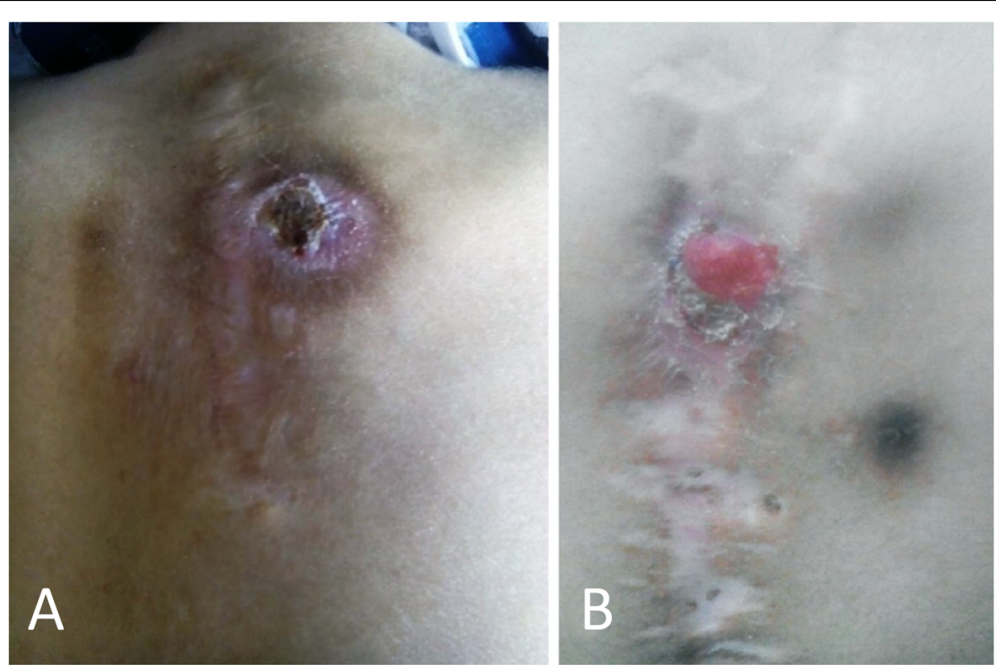

Fig. 1 A 25-month-old boy (a) and 30-month-old girl (b) with scoliosis, operated by adult-specific pedicle screws. Note hardware prominence leading to skin breakdown. Revision surgery was done for both patients 


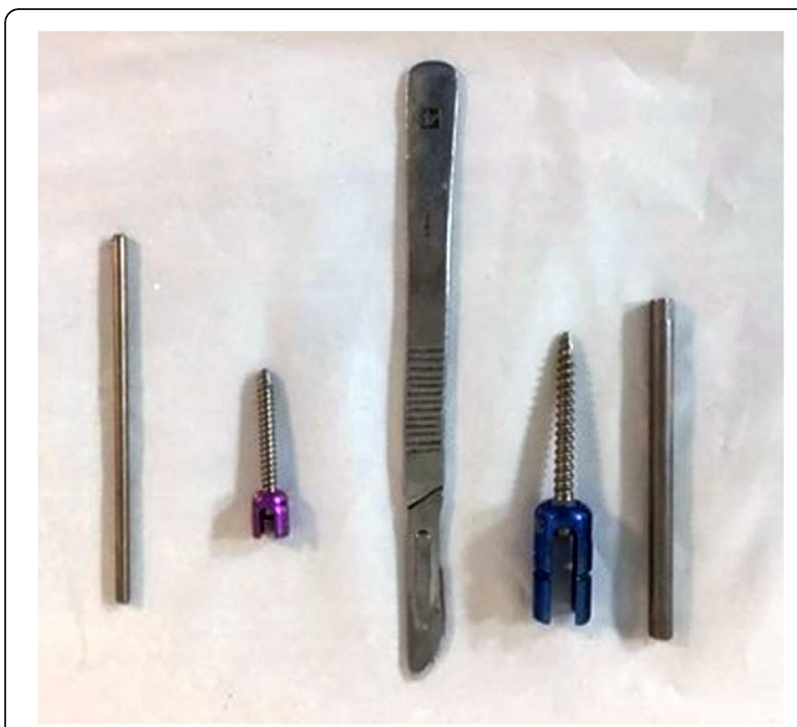

Fig. 2 A 3.5-mm cervical lateral mass screw and rod (left) and a 4.5$\mathrm{mm}$ adult-specific pedicle screw and rod (right)

either in the early or late post-operative period, were identified and recorded.

A thorough physical examination and radiographic evaluation were performed for accompanying congenital anomalies. A pre-operative CT scan with reconstruction was done to choose the appropriate instrument and evaluate the pedicle morphology. To assess intracanal anomalies, a pre-operative spine MRI was performed in all patients, which revealed syringomyelia in one patient and a tethered cord, neither of which required a change in the surgical plan.

\section{Surgical technique}

All patients underwent a standard resection of the hemivertebra using a single-stage posterior approach. Fixation and fusion of the adjacent vertebrae were performed using transpedicular instrumentation with lateral mass screws and rod.

All screws were placed with a free-hand technique, and a correct placement was confirmed with fluoroscopy. The thoracic vertebrae's starting point was the intersection of a vertical line immediately lateral to the midpoint of the facet joint and a horizontal line at the superior third of the transverse process. In the lumbar spine, the intersection of a vertical line that passes along the lateral aspect of the facet joint and a horizontal line that bisects the transverse process was chosen as the entry point. Using a rongeur, the entry point was decorticated, and a passage in the pedicle was initially gained using a 2-mm curved probe. The pedicle feeler was used to check the passage. A 3.5 - or 4-mm polyaxial lateral mass screw with an appropriate length was subsequently inserted into the pedicle (Fig. 3). The fusion only included the two vertebrae adjacent to the resected hemivertebra. In case of a significant kyphosis, severe scoliosis, pedicle fracture, or insecure fixation, fusion was extended for one or two additional segments.

A standard posterior hemivertebra resection was performed with resection of the facets, lamina, and the hemivertebra's transverse process to expose the pedicle. The upper and lower nerve roots were then explored. In the thoracic spine, the transverse process, the rib head, and the proximal part of the rib on the convex side were resected. The pedicle's remnants, the discs adjacent to the hemivertebra, and the hemivertebra's vertebral body were removed, and the adjacent vertebra end plates are
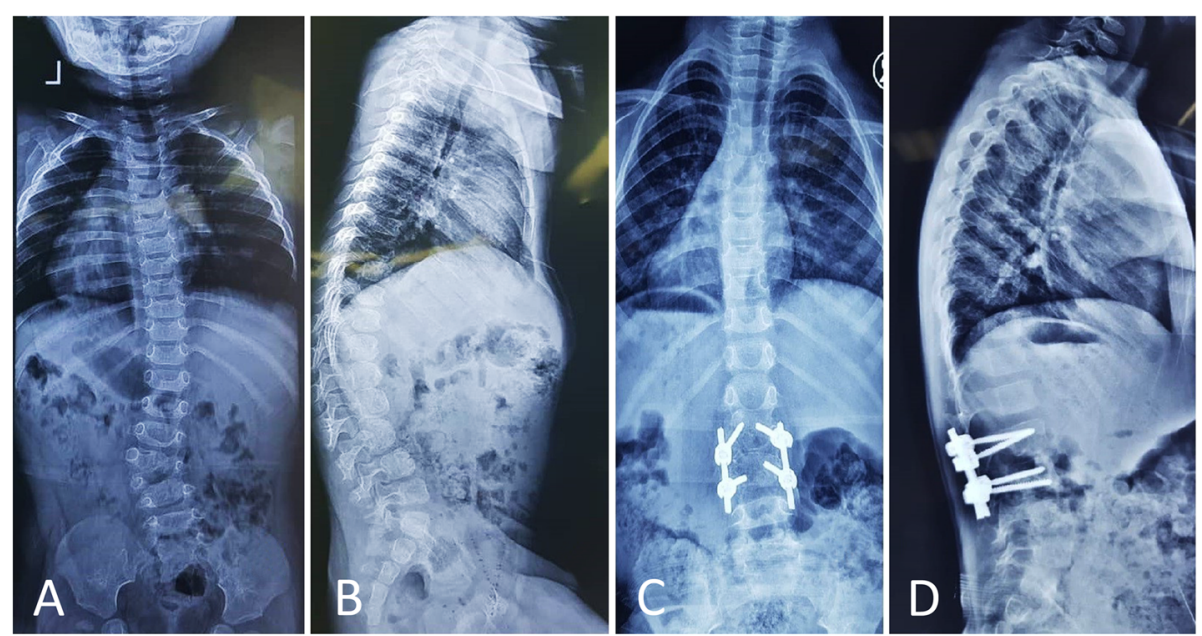

Fig. 3 An 18-month-old boy with congenital lumbar hemivertebra. Pre-operative radiographs (a, b) show a fully segmented hemivertebra in the lumbar region with coronal segmental scoliosis of $39^{\circ}$ and segmental kyphosis of $16^{\circ}$. Post-operative radiographs (c, d) after hemivertebra resection and internal fixation with lateral mass screws. The coronal curve was corrected to $5^{\circ}$ and the sagittal to $1^{\circ}$ 
debrided down to bleeding bone. In cases with a large hemivertebra or with substantial kyphosis, an autologous bone graft and mesh cage were used to provide stability and correct the kyphosis. After contouring and insertion of the rod, compression was applied on the convex side until the gap was closed completely. If the gap persisted, cancellous bone graft was used in the gap.

All patients were intraoperatively monitored with somatosensory-evoked potentials (SSEP) and motorevoked potential (MEP) neuromonitoring. Patients were mobilized in the first post-operative week, and an orthosis was used for 3-6 months when awake.

\section{Statistical analysis}

To analyze the difference between pre-operative, postoperative, and final follow-up values, paired student's $t$ tests were used. All statistical analyses were performed using IBM SPSS Statistics for Windows, Version 22.0 (Armonk, NY). The level of significance was considered as $P<0.05$.

\section{Results}

Twenty-three patients (14 females, nine males) were included in the final analysis, with a mean age of 40 months at the time of surgery (range, 27-60 months). Patients were followed for a mean of $51.3 \pm 13.2$ months post-operatively (range, 26-88 months).

The hemivertebra was located in the thoracic spine (T1-T9) in nine patients (39\%), thoracolumbar region (T10-L2) in ten patients (44\%), and lumbar spine (L3L4) in four patients (17\%). Sixteen hemivertebrae (70\%) were fully segmented, while seven (30\%) were semisegmented. None of the hemivertebrae was incarcerated. Associated anomalies were present in seven patients (30\%), including intraspinal anomalies (3 patients), brain pathologies ( 2 patients), cardiopulmonary (1 patient), and genitourinary system (1 patient) anomalies.

Overall, lateral mass screws were inserted in T3 to L5 vertebrae, with a diameter of $3.5 \mathrm{~mm}$ in the T1-T12 vertebrae and $4 \mathrm{~mm}$ in L1-L5. The mean screw length was $26 \mathrm{~mm}$ (range, $20-30 \mathrm{~mm}$ ) in the thoracic spine (T1-
T12) and 30mm (range, 24-36mm) in the lumbar spine (L1-L5). In three patients with significant kyphosis and curves $>50^{\circ}$, one additional segment was added to the fusion to avoid overloading the construct and reduce the risk of pedicle fracture or implant failure.

The mean operation time was 143 min (range, 90-270 min). The average blood loss was $210 \mathrm{ml}$ (range, 70 $430 \mathrm{ml})$. Patients were admitted for a median of 4 days (range, 3-7 days). All patients wore a brace for a mean of 4 months (range, 3-6.5 months) and were mobilized with a brace within the first post-operative week.

The mean Cobb angle of the main coronal curve was $42.5^{\circ}$ before surgery (range, $18^{\circ}-72^{\circ}$ ), which was corrected to a mean of $8.5^{\circ}$ (range, $3^{\circ}-39^{\circ}$ ) immediately after surgery. The mean segmental sagittal kyphosis (difference from the normal value [6]) was $19.3^{\circ}$ preoperatively (range, $4^{\circ}-36^{\circ}$ ), which was corrected to a mean of $8.8^{\circ}$ post-operatively. While all measurements showed a significant improvement in the post-operative radiographs, the difference between immediate post-operative and latest follow-up measurements was not statistically significant (Table 1).

There were no neurologic, vascular, or visceral complications, respiratory problems, or death in any of the patients. The only intra-operative complication was a convex pedicle fracture in one patient, which was managed by extending the fusion by one level. None of the patients had hardware-related skin breakdown or complained of hardware prominence. One patient experienced a surgical site infection, which resolved with surgical irrigation and debridement and antibiotics. In one case, implant failure was observed due to screw pull out 1 year after the index procedure, which was treated with an uneventful revision. One patient had a $10^{\circ}$ increase in the cobb angle of the main curve in the follow-up period, which was managed by continuing the brace for four additional months, after which the curve stabilized and went on to fuse uneventfully. Proximal junctional kyphosis was not observed in any patient.

Table 1 Correction are achieved among patients in this series. Values are presented as mean \pm SD (range). Significant $P$ values are indicated in italic

\begin{tabular}{|c|c|c|c|c|c|c|}
\hline & $\begin{array}{l}\text { Pre- } \\
\text { operative }\end{array}$ & $\begin{array}{l}\text { Post- } \\
\text { operative }\end{array}$ & $\begin{array}{l}P \text { value (pre-op to } \\
\text { post-op) }\end{array}$ & $\begin{array}{l}\text { Correction } \\
\text { rate }(\%)\end{array}$ & $\begin{array}{l}\text { Latest } \\
\text { follow-up }\end{array}$ & $\begin{array}{l}P \text { value (post-op to latest } \\
\text { follow-up) }\end{array}$ \\
\hline Main curve $\left(^{\circ}\right)$ & $\begin{array}{l}42.5 \pm 10.1 \\
(18-72)\end{array}$ & $\begin{array}{l}8.5 \pm 7.2 \\
(3-39)\end{array}$ & 0.001 & 75 & $\begin{array}{l}10.7 \pm 7.5 \\
(2-35)\end{array}$ & 0.1 \\
\hline Compensatory cranial curve $\left(^{\circ}\right)$ & $\begin{array}{l}16.2 \pm 10.7 \\
(3-35)\end{array}$ & $\begin{array}{l}4.1 \pm 2.9 \\
(1-16)\end{array}$ & $<0.001$ & 68 & $\begin{array}{l}5.1 \pm 4.4 \\
(2-16)\end{array}$ & 0.06 \\
\hline Compensatory caudal curve $\left(^{\circ}\right)$ & $\begin{array}{l}19.3 \pm 12.4 \\
(5-75)\end{array}$ & $\begin{array}{l}6.2 \pm 6.1 \\
(5-34)\end{array}$ & $<0.001$ & 65 & $\begin{array}{l}6.7 \pm 6.4 \\
(3-35)\end{array}$ & 0.5 \\
\hline $\begin{array}{l}\text { Segmental kyphosis (difference from } \\
\text { normative values) }\end{array}$ & $\begin{array}{l}19.1 \pm 8.6(4- \\
36)\end{array}$ & $\begin{array}{l}8.8 \pm 5.1 \\
(-2-19)\end{array}$ & 0.002 & 69 & $\begin{array}{l}6 \pm 7.1(-4- \\
23)\end{array}$ & 0.08 \\
\hline
\end{tabular}




\section{Discussion}

In this study, we reported hemivertebra resection and posterior fusion results with lateral mass screws in 23 patients with congenital scoliosis. Our findings suggest that in the lack of pediatric-specific pedicle screws, lateral mass screws from an adult cervical set can successfully be used for posterior fusion in children under 5 years.

Pediatric-specific spinal instruments are not readily available at many centers, especially in the developing world, due to the cost and limited application of such instruments. However, adult instruments have been in the market for decades, are less expensive, and are available at any spine surgery center. The potential solutions to the lack of pediatric-specific implants are to use adulttype implants in older children, postpone surgery in younger children, and subsequently use adult implants, or use hooks instead of pedicle screws. We argue that neither of these solutions is ideal, and they might result in suboptimal outcomes and complications [7].

A swift curve progression is typically observed in segmented hemivertebrae due to their imbalanced growth potential. The curve will grow and become more rigid and hard to correct if left untreated. Also, the development of compensatory curves will further complicate treatment [8]. Early treatment diminishes the need for extensive procedures and mitigates the need to correct compensatory curves. Early resection of the hemivertebra and short-segment posterior fusion is the current standard of care in congenital hemivertebra. In a cohort of congenital scoliosis patients, Chang et al. have shown that patients treated before the age of 6 years have a significantly better deformity correction compared to after 6 years of age. They did not observe a disturbing vertebral/spinal growth in patients who received early treatment [9].

Compared with non-rigid constructs, pedicle screws offer a three-column control of the spine, a superior control to correct the deformity, higher fusion rates, and lower implant failures and pseudarthrosis [10-13]. Even in children younger than 5 years old, pedicle screw constructs are safe and efficient $[14,15]$. Ruf et al. have reported the safety and efficacy of pedicle screws even in 1 - and 2-year-old children [16]. We have previously used adult-type pedicle screws in children who had a sufficient pedicle diameter to accommodate larger screws but have experienced unacceptably high skin breakdown rates and complaints of prominent hardware from almost all patients/parents. We have therefore abandoned the practice despite otherwise excellent results. We have been using lateral mass screws as pedicle screws in children younger than 5 years old and have been satisfied with the technique, results, and the low rate of complications. Lateral mass screws are low-profile, readily available at most centers, and have an appropriate structure and diameter to be used as pedicle screws in children. In our series, the mean age at the surgery time was 40 months, with all patients undergoing surgery before 5 years, which is the ideal age of treatment in congenital scoliosis. The use of lateral mass screws in lieu of pediatric-specific pedicle screws has allowed us to provide the highest standard-of-care for our patients without sacrificing the results or subjecting them to undue risk of complications. While lateral mass screws are successfully used in the adult and pediatric cervical spine to provide three-column fixation, their use as pedicle screws has not been reported previously. This technique may also be combined with 3D-printed spine models or guides, which would serve as an educational tool for the family and the medical team, and also increase the precision of the pre-operative planning $[17,18]$.

In our study, the mean percent correction of the main coronal curve, segmental sagittal angles, compensatory caudal, and compensatory cranial curves were $74.8 \%, 68.9 \%, 68 \%$, and $65.2 \%$, respectively. In a retrospective study of 28 patients with congenital scoliosis, Ruf et al. [14] reported a correction rate of $72 \%$ for the main curve, $78 \%$ for the compensatory cranial curve, 65\% compensatory caudal curve, and $63 \%$ for kyphosis. Other studies have also reported similar correction rates (Table 2) [3, 19, 20].

Overall, we had three complications among our patients (13\%), including one intra-operative pedicle fracture, one deep infection, and one implant failure. All complications were managed according to accepted guidelines, and neither resulted in long-term complication or morbidity. Guo et al. reported a $7 \%$ rate of complications [3], while Ruf and Harms reported a 21\% rate of complications in their respective series [14]. While revision surgery for screw malposition has been reported in 0.8 to $4.3 \%$ of children and adults undergoing posterior instrumentation, none of our patients needed such a revision surgery [21-25].

Table 2 Summary of previous studies

\begin{tabular}{lllllll}
\hline First author & Year & Cases & Mean correction rate & Implant failure & Total number of complications (\%) & Repeat surgery \\
\hline Ruf and Harms [14] & 2003 & 28 & $69.5 \%$ & 3 & $6(21 \%)$ & 4 \\
Guo et al. [3] & 2016 & 39 & 74.5 & 0 & $3(7 \%)$ & 4 \\
Erden et al. [19] & 2017 & 9 & $81 \%$ & 0 & $0(0 \%)$ & 0 \\
Xue and Zao [20] & 2018 & 43 & $69 \%$ & 0 & $4(9.3)$ & 4 \\
\hline
\end{tabular}


This study has several limitations, including those inherent in a retrospective case series. While the small study population is in line with previous studies and is due to the procedure being relatively uncommon, it precludes making strong suggestions and recommendations. However, one surgeon performed all surgeries, and we will also be conducting follow-up studies with control groups. Additionally, we do not perform routine intra- or post-operative CT scans and, therefore, could not evaluate minor malpositions. However, none of our patients had a grossly malpositioned screw or a complication of such malposition. Finally, we did not report patientreported outcomes in this study, although one would assume that hardware choice will not significantly affect the quality of life.

\section{Conclusions}

Our findings suggest that adult lateral mass screws can be used for transpedicular fixation of the thoracic and lumbar vertebrae in low-resource settings where pediatric-specific pedicle instruments are not readily available. The correction rate, outcomes, and complications are similar and comparable to pediatric-specific pedicle screws, in addition to being low-profile and less bulky compared to adult implants.

\section{Abbreviations}

CT: Computed tomography; MRI: Magnetic resonance imaging;

SSEP: Somatosensory evoked potentials; MEP: Motor-evoked potentials;

PJK: Proximal junctional kyphosis

\section{Acknowledgements}

None

\section{Authors' contributions}

Study design and conceptualization: MZ, EG, NB, SMMMJ, and AM. Data collection: $\mathrm{EG}, \mathrm{NB}, \mathrm{AM}$, and MM. Data analysis: NB, SMMMJ, SB, and MM. Manuscript drafting: $M Z, E G$, and $S B$. Revising the manuscript: $M Z, E G$, and SB. The authors have read and approved the final version of the manuscript.

\section{Funding}

No funding was received for this study.

\section{Availability of data and materials}

The datasets used and/or analyzed during the current study are available from the corresponding author on reasonable request.

\section{Declarations}

Ethics approval and consent to participate

The institutional review board of Tehran University of Medical Sciences reviewed and approved the study protocol, with a waiver of written consent due to the retrospective nature of the study. All patients/parents were informed that their data will be used in the study, and all gave verbal consent.

\section{Consent for publication}

Not applicable.

\section{Competing interests}

The authors declare that they have no competing interests.
Received: 9 March 2021 Accepted: 11 April 2021

Published online: 17 April 2021

\section{References}

1. Winter RB, Moe J, Lonstein J. Posterior spinal arthrodesis for congenital scoliosis. An analysis of the cases of two hundred and ninety patients, five to nineteen years old. JBJS. 1984;66(8):1188-97. https://doi.org/10.2106/ 00004623-198466080-00006.

2. Bollini G, Docquier P-L, Viehweger E, Launay F, Jouve J-L. Thoracolumbar hemivertebrae resection by double approach in a single procedure: longterm follow-up. Spine. 2006;31(15):1745-57. https://doi.org/10.1097/01.brs. 0000224176.40457 .52 .

3. Guo J, Zhang J, Wang S, Zhang $Y$, Yang $Y$, Yang $X$, et al. Surgical outcomes and complications of posterior hemivertebra resection in children younger than 5 years old. J Orthop Surg Res. 2016;11(1):48. https://doi.org/10.1186/ s13018-016-0381-2.

4. Linden AF, Sekidde FS, Galukande M, Knowlton LM, Chackungal S, McQueen KA. Challenges of surgery in developing countries: a survey of surgical and anesthesia capacity in Ugand's public hospitals. World J Surg. 2012;36(5): 1056-65. https://doi.org/10.1007/s00268-012-1482-7.

5. Nundy S. Difficulties of surgery in the developing world: a personal view. Lancet. 1999;353:S21-3. https://doi.org/10.1016/S0140-6736(99)90225-8.

6. Bernhardt $\mathrm{M}$, Bridwell $\mathrm{KH}$. Segmental analysis of the sagittal plane alignment of the normal thoracic and lumbar spines and thoracolumbar junction. Spine. 1989;14(7):717-21. https://doi.org/10.1097/00007632-1 98907000-00012.

7. Baghdadi S, Mortazavi SMJ, Baghdadi T. The Ever-elusive Concept of Clinical Judgment. J Pediatr Orthop. 2021;41(1):e100-1. https://doi.org/10.1 097/BPO.0000000000001668.

8. Winter RB, Moe JH, Eilers VE. Congenital scoliosis a study of 234 patients treated and untreated: part I: natural history. JBJS. 1968;50(1):1-15. https:// doi.org/10.2106/00004623-196850010-00001

9. Chang D-G, Kim J-H, Ha K-Y, Lee J-S, Jang J-S, Suk S-I. Posterior hemivertebra resection and short segment fusion with pedicle screw fixation for congenital scoliosis in children younger than 10 years: greater than 7-year follow-up. Spine. 2015;40(8):E484-91. https://doi.org/10.1097/ BRS.0000000000000809.

10. Belmont PJ Jr, Klemme WR, Dhawan A, Polly DW Jr. In vivo accuracy of thoracic pedicle screws. Spine. 2001;26(21):2340-6. https://doi.org/10.1097/ 00007632-200111010-00010

11. Liljenqvist U, Lepsien U, Hackenberg L, Niemeyer T, Halm H. Comparative analysis of pedicle screw and hook instrumentation in posterior correction and fusion of idiopathic thoracic scoliosis. Eur Spine J. 2002;11(4):336-43. https://doi.org/10.1007/s00586-002-0415-9.

12. Liljenqvist UR, Halm HF, Link TM. Pedicle screw instrumentation of the thoracic spine in idiopathic scoliosis. Spine. 1997;22(19):2239-45. https://doi. org/10.1097/00007632-199710010-00008.

13. Suk S-I, Kim W-J, Lee S-M, Kim J-H, Chung E-R. Thoracic pedicle screw fixation in spinal deformities: are they really safe? Spine. 2001;26(18):204957. https://doi.org/10.1097/00007632-200109150-00022.

14. Ruf M, Harms J. Hemivertebra resection by a posterior approach: innovative operative technique and first results. Spine. 2002;27(10):1116-23. https://doi. org/10.1097/00007632-200205150-00020.

15. Zarei M, Tavakoli M, Ghadimi E, Moharrami A, Nili A, Vafaei A, et al. Complications of dual growing rod with all-pedicle screw instrumentation in the treatment of early-onset scoliosis. J Orthop Surg Res. 2021;16(1):1-6.

16. Ruf M, Harms J. Pedicle screws in 1-and 2-year-old children: technique, complications, and effect on further growth. Spine. 2002;27(21):E460-6. https://doi.org/10.1097/00007632-200211010-00019.

17. Tevanov L, Liciu E, Chirila MO, Dusca A, Ulici A. The use of 3D printing in improving patient-doctor relationship and malpractice prevention. Rom J Leg Med. 2017;25(3):279-82. http://www.rjlm.ro/index.php/arhiv/578.

18. Baghdadi S, Baghdadi T. How old is too young for hip preservation surgery: femoral head reduction osteotomy for the sequela of traumatic hip dislocation in a six-year-old with the aid of 3D-printed models. IJOS. 2020;18 (4):158-63.

19. Erturer RE, Kilinc BE, Gokcen B, Erdogan S, Kara K, Ozturk C. The results of hemivertebra resection by the posterior approach in children with a mean follow-up of five years. Adv Orthoped. 2017;2017.

20. Xue $X$, Zhao S. Posterior hemivertebra resection with unilateral instrumented fusion in children less than 10 years old: preliminary results at 
minimum 5-year follow-up. J Orthop Surg Res. 2018;13(1):240. https://doi. org/10.1186/s13018-018-0946-3.

21. Parker SL, McGirt MJ, Farber SH, Amin AG, Rick A-M, Suk I, et al. Accuracy of free-hand pedicle screws in the thoracic and lumbar spine: analysis of 6816 consecutive screws. Neurosurgery. 2011;68(1):170-8. https://doi.org/10.1227/ NEU.0b013e3181fdfaf4.

22. Hicks JM, Singla A, Shen FH, Arlet V. Complications of pedicle screw fixation in scoliosis surgery: a systematic review. Spine. 2010;35(11):E465-70. https:// doi.org/10.1097/BRS.0b013e3181d1021a.

23. Ravi B, Zahrai A, Rampersaud R. Clinical accuracy of computer-assisted twodimensional fluoroscopy for the percutaneous placement of lumbosacral pedicle screws. Spine. 2011;36(1):84-91. https://doi.org/10.1097/BRS.0b013 e3181cbfd09.

24. Watkins RG IV, Gupta A, Watkins RG III. Cost-effectiveness of image-guided spine surgery. Open Orthopaed J. 2010;4(1):228-33. https://doi.org/10.21 74/1874325001004010228.

25. Di Silvestre M, Parisini P, Lolli F, Bakaloudis G. Complications of thoracic pedicle screws in scoliosis treatment. Spine. 2007;32(15):1655-61. https://doi. org/10.1097/BRS.0b013e318074d604.

\section{Publisher's Note}

Springer Nature remains neutral with regard to jurisdictional claims in published maps and institutional affiliations.

Ready to submit your research? Choose BMC and benefit from:

- fast, convenient online submission

- thorough peer review by experienced researchers in your field

- rapid publication on acceptance

- support for research data, including large and complex data types

- gold Open Access which fosters wider collaboration and increased citations

- maximum visibility for your research: over $100 \mathrm{M}$ website views per year

At $\mathrm{BMC}$, research is always in progress.

Learn more biomedcentral.com/submissions 